Research Article

\title{
INVESTIGATION OF MECHANICAL AND THERMAL BEHAVIOR OF BASALT CUTTING WASTE (BCW) ADDED CLAY BRICK
}

\begin{abstract}
Şermin KOÇYİĞIT ${ }^{1 *}$, Vedat Veli ÇAY ${ }^{2}$
Porous clay bricks produced by adding 5\%,10\%, 15\% and $20 \%$ by weight of Basalt Cutting Waste (BCW) were manufactured by semi-dry pressing process. BCW (Karacadăg, Diyarbakir, Turkey) was added to brick raw material as an additive in order to increase porosity and strength. The chemical composition and thermal behaviors of raw materials were investigated and SEM analysis was performed. Brick mixes containing different proportions of $B C W$ were formed and then fired at 900 and $1000^{\circ} \mathrm{C}$ for two hours. Porosity, water absorption, compressive strength, thermal conductivity and microstructure of the samples were examined. It was observed that the porosity ratios were increased by up to $34 \%$ with the addition of BCW, however, compressive strength (at least $28 \mathrm{MPa}$ ) decreased. However, the compressive strength was found to be higher than the required standards. The thermal conductivity of samples with the addition of $20 \%$ BCW decreased from 0.98 up to $0.72 \mathrm{~W} / \mathrm{mK}$ compared to the reference sample, which also corresponds to a reduction of $26.5 \%$ in proportion to the reference sample along with the increase in porosity. The increase in firing temperature also affected the mechanical and physical properties of the samples. In conclusion, this study revealed that the brick samples produced could be evaluated and used as insulating materials by adding BCW to building materials in construction applications.
\end{abstract}

Key words: Clay brick, Basalt, Physical properties, Mechanical properties, Thermal conductivity

\section{Introduction}

Recently, energy consumption of the buildings all over the world has become the most important problem. The energy consumed for the buildings in the world is generally used for heating and cooling. This consumption rate is approximately one third of the energy used in the world [1,2]. In this context, many countries in the world aim to reduce energy consumption in buildings. It is surely known that both economic and environmental concerns come to the forefront in the realization of these targets. Due to these concerns, it is most profitable and preferred solution is to improve thermal insulation properties in order to reduce energy consumption in buildings [3]. Approximately 30\% of energy or heat loss in buildings passes through walls. [4-6]. The bricks used in walls are the most common construction

\footnotetext{
1 Department of Construction Technology, Technical Sciences Vocational School, Dicle University, Diyarbakır, Turkey, (sermin.kocyigit@dicle.edu.tr) Đhttps://orcid.org/0000-0002-7283-8967

2 Department of Airframes and Powerplants, School of Civil Aviation, Dicle University, Diyarbakır, Turkey (vcay@dicle.edu.tr) (ic https://orcid.org/0000-0002-2770-4038
} 
materials. Bricks should have good thermal insulation behaviors as well as mechanical properties. Fired clay bricks, which are the most well-known type of bricks and among the oldest known construction materials, are preferred because of their simple and reliable construction technique, relatively low cost and low maintenance cost, physical properties [7]. In addition, the bricks also offer a comfortable moisture environment with mechanical and thermal properties in buildings. [8]. The quality of the brick is highly dependent on the properties and composition of the raw materials, the production procedure, the firing method, and the temperature and time [9-11] The sintering process in clay bricks increases the strength of bricks. Sintering is the binding mechanism of clay particles and it can only be achieved under the influence of heat [12]. Furthermore, the thermal performance of bricks depends on the geometry of the pores formed in the brick $[13,14]$. If the porous structure of clay bricks is improved by appropriate methods, they may have a significantly lower thermal conductivity and permeability properties, which means that a lower heat loss can be achieved on the walls of homes $[15,16]$. Bricks can be formed with micropores by adding various organic and inorganic pore-forming additives (such as closed pores) to brick raw material mixtures before firing [17]. Some different pore-forming materials such as wood sawdust, polymers, leather residues, organic residues, coal dust, powder limestone, paper sediment and mineral additives providing thermal decomposition were commonly used .Heat resistant porous materials such as diatomite, zeolite, vermiculite and perlite were also utilized in ceramic bricks. $[5,6,18-$ 20].

Basalt is among the volcanic rocks in the classification of natural stones. Basalt, which is a dark gray and black volcanic rock that is mainly composed of feldspar and found in nature with crystalline and dense pulp or glassy nature, is widely available with various properties in Diyarbakır and Afyon provinces and in the Thrace region in Turkey [21].

Basalt deposits in Diyarbakır-Karacadağ cover large areas in the Southeastern Anatolia Region of Turkey. The basalt flow from the Karacadağ volcano, which provides the formation of these basalt stones, is widespread in an area of approximately 80 meters thick and $10.000 \mathrm{~m} 2$, especially in three regions of Diyarbakır [22]. Large basalt plateaus with a diameter of 120-130 km are observed in the regions on the way to Diyarbakır-Şanlıurfa in the west, Diyarbakır-Elazığ in the north and DiyarbakırMardin in the east. [23]. Basalt blocks are cut and sized according to the areas of usage. Basalt powders, which are characterized as waste, are formed during this cutting process. These waste powders are stored by business owners in an area that is not operational. The high abrasion resistance, low thermal conductivity, and resistance to acid and frost of the Diyarbakır-Karacadağ basalt have ensured the diversification of the areas of usage and have led to an increase in the studies related to this material. The geological, petrographic, tectonic and basalt-marble properties of different regions basalts of Turkey have been investigated with the studies conducted to date [24-29]. However, it was determined that there were no studies regarding the utilization of waste basalt cutting powders in the literature. Thus, the aim of this study was to determine of feasibility of using the waste basalt powder in production of clay brick samples and the effects on physical and mechanical properties and thermal conductivity of bricks.

\section{Mterials and Methods}

In this study, it was aimed to produce brick samples from clay mixtures with BCW addition in order to be used as an insulating material. The mechanical and thermal behaviors of BCW additive in powder form in ratios of $5 \%, 10 \%, 15 \%, 20 \%$ by weight in clay bricks were examined. 
Table 1. Mixture proportions.

\begin{tabular}{cccc}
\hline Mix code & Fring temperature/time & Brick clay(wt.\%) & Basalt(wt.\%) \\
\hline S0 & $900^{\circ} \mathrm{C} / 2 \mathrm{~h}$ & 100 & 0 \\
S1 & $900^{\circ} \mathrm{C} / 2 \mathrm{~h}$ & 95 & 5 \\
S2 & $900^{\circ} \mathrm{C} / 2 \mathrm{~h}$ & 90 & 10 \\
S3 & $900^{\circ} \mathrm{C} / 2 \mathrm{~h}$ & 85 & 15 \\
S4 & $900^{\circ} \mathrm{C} / 2 \mathrm{~h}$ & 80 & 20 \\
P0 & $1000^{\circ} \mathrm{C} / 2 \mathrm{~h}$ & 100 & 0 \\
P1 & $1000^{\circ} \mathrm{C} / 2 \mathrm{~h}$ & 95 & 5 \\
P2 & $1000^{\circ} \mathrm{C} / 2 \mathrm{~h}$ & 90 & 10 \\
P3 & $1000^{\circ} \mathrm{C} / 2 \mathrm{~h}$ & 85 & 15 \\
P4 & $1000^{\circ} \mathrm{C} / 2 \mathrm{~h}$ & 80 & 20 \\
\hline
\end{tabular}

The mixture ratios are presented in Tab. 1. The clay raw material was obtained from the brick manufacturer and the BCW was obtained from the basalt processing plant (in Diyarbakır, Turkey). Clay and BCW were first subjected to pretreatments such as drying, grinding and sieving. Raw materials with a particle size of less than $150 \mu \mathrm{m}$ were used for the production of bricks. They were mechanically mixed in a laboratory mixer with sprayed water for approximately $15 \%$ of total weight for 30 minutes to obtain homogeneity and density in the mixtures.

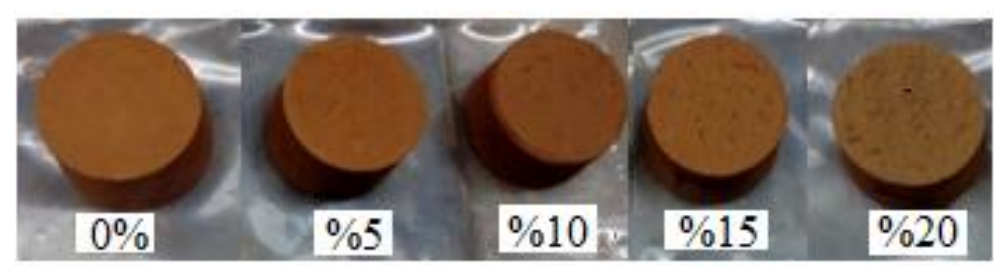

Figure 1. Brick production

For each test, brick samples with $\emptyset=3 \mathrm{~cm}, \mathrm{~h}=2 \mathrm{~cm}$ sizes were semi-dry pressed to a mold with a hydraulic press under a pressure of $10 \mathrm{MPa}$ and kept at room temperature overnight. The samples were dried in the furnace at $40^{\circ} \mathrm{C}$ for 20 hours and then at $100^{\circ} \mathrm{C}$ for 18 hours. After drying, the samples were fired in a laboratory electric furnace (Protherm PLF12 / 15) at a rate of $5^{\circ} \mathrm{C} / \mathrm{min}$ for 2 hours at $900^{\circ} \mathrm{C}$ and $1000^{\circ} \mathrm{C}$. The samples fired at $1000^{\circ} \mathrm{C}$ are presented in Fig. 1 . Then, the water absorption, porosity, compressive strength and thermal conductivity values of these samples were measured. The measurements of thermal conductivity values were performed using the C-Therm TCi Thermal Conductivity Analyzer [9].

\subsection{Thermal conductivity measurements}

Although the thermal conductivity analyzer measure with an error of less than $0.4 \%$, the mathematical discussion of the error was examined in this study. Because the error is important on the thermal performance of the material. The basic procedure for examining and minimizing the error in thermal measurements is presented below: 
- At least three different samples are tested under three different thermal and moisture conditions of each material.

- Each test consists of at least ten thermal measurements.

- The characteristic thermal conductivity value is obtained for ninety tests under three different thermal and moisture conditions, considering the average value in each sample.

\section{Results and Discussion}

\subsection{Characterization of the raw material}

The chemical compositions of clay and $\mathrm{BCW}$ raw material made by XRF analysis are presented in Tab. 2.

Table 2. Chemical composition of raw material (wt.\%).

\begin{tabular}{ccc}
\hline Oxides & Clay & BKA \\
\hline $\mathrm{SiO}_{2}$ & 59.9 & 46.04 \\
$\mathrm{Al}_{2} \mathrm{O}_{3}$ & 16.1 & 13.89 \\
$\mathrm{Fe}_{2} \mathrm{O}_{3}$ & 7.3 & 4.89 \\
$\mathrm{CaO}$ & 2.08 & 9.12 \\
$\mathrm{MgO}$ & 2.12 & 8.76 \\
$\mathrm{~K} 2 \mathrm{O}$ & 2.33 & 1.04 \\
$\mathrm{Na}_{2} \mathrm{O}$ & 0.81 & 3.64 \\
$\mathrm{SO}_{3}$ & - & - \\
Loss on ignition & 9.36 & 12.62 \\
\hline
\end{tabular}
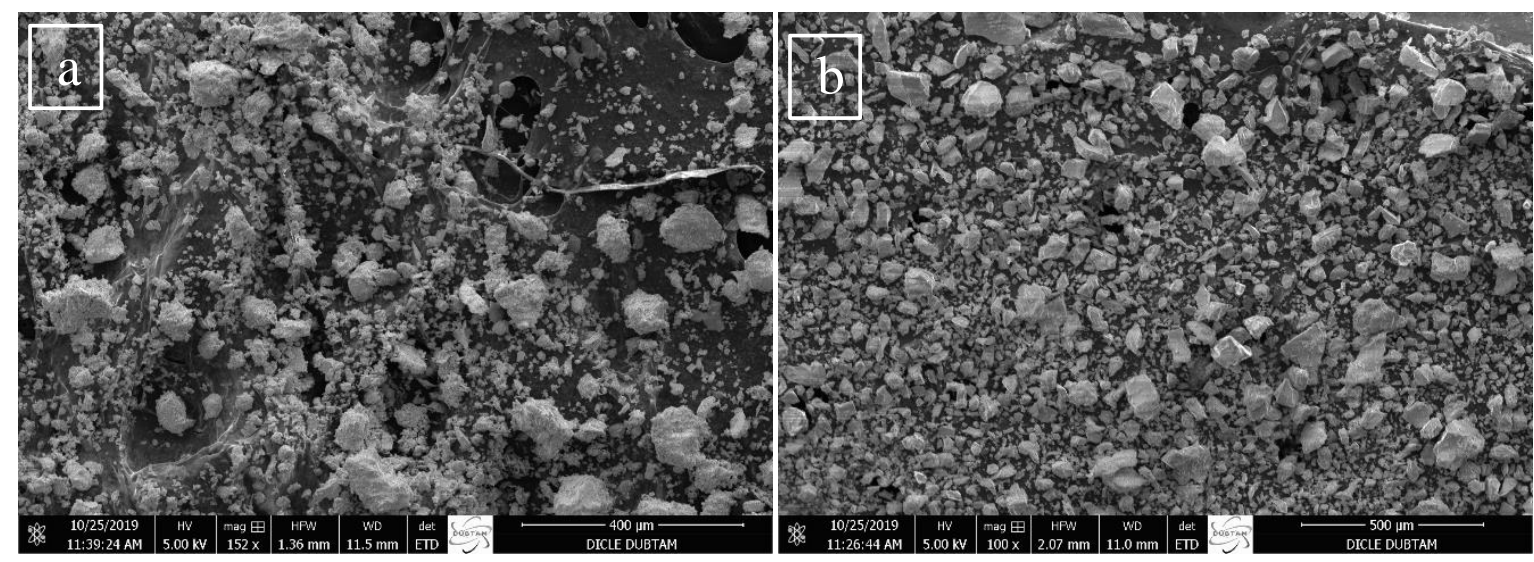

Figure 2. Raw material morphologies a) clay, b) BCW

SEM images of clay and BCW raw materials after sieving are presented in Fig. 2. Brick clay contains aluminum, iron, calcium, magnesium and potassium oxides as well as a large silica fraction. Basalt, which is one of the volcanic stone masses, is the most important stone of the gabbro family with its dark color, microlithic or glassy texture and homogeneous structure. The composition of the basalt includes basic feldspar such as augite microliths, enerphit and labrador, magnetite and olivine granules, and also sometimes substances such as ilmenite and hornblende. 


\subsection{Characterization of the fired samples}

\subsubsection{Apparent porosity}

The porosity values of the produced bricks are presented in Fig. 3. As it is seen in Figure 3, the porosity ranged from $28.4 \%$ to $33.8 \%$. The lowest porosity was obtained at P0.

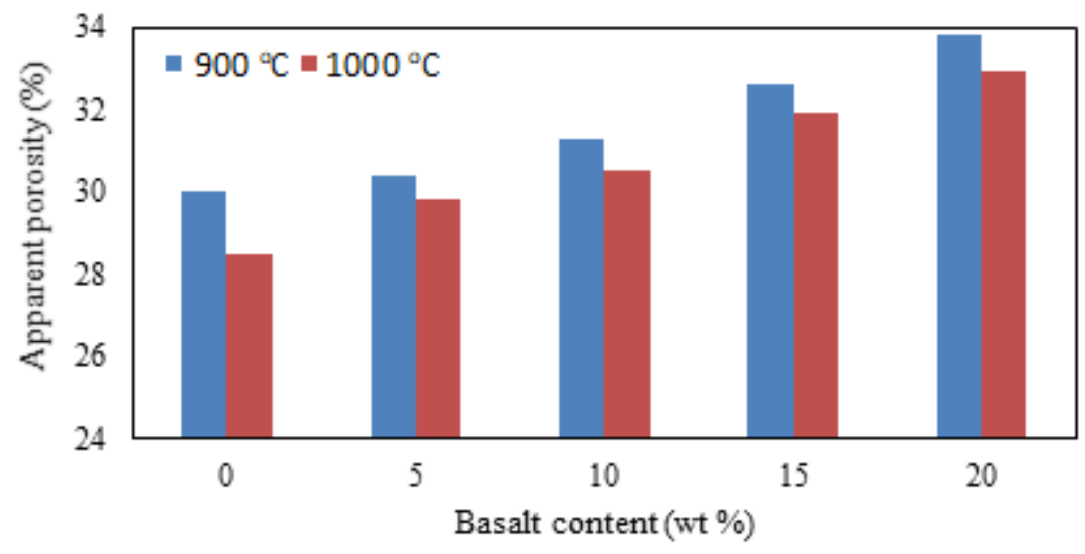

Figure 3. Apparent porosity of the produced bricks.

The highest porosity was observed in S4. As it is seen in Fig. 3, the difference between the two reference bricks ( $\mathrm{S} 0$ and $\mathrm{P} 0$ ) was $5.1 \%$. When the porosities of $\mathrm{S} 1, \mathrm{~S} 2, \mathrm{~S} 3$ and S4 were compared with S0, they were higher by $1.3 \%, 4.3 \%, 8.7 \%$ and $12.6 \%$, respectively. When the porosities of P1, P2, P3 and P4 were compared with P0, porosity ratios were higher by $4.8 \%, 7.3 \%, 12.1 \%$ and 15.7\%, respectively.

As it is understood, the addition of BCW in the brick had a significant effect on the porosity of the samples since it increased the porosity slightly at both temperatures. When each group containing the same $\mathrm{BCW}$ ratio was examined to see the effect of the fire temperature, the largest difference was found to be $5.1 \%$ between S0 and P0. As it is seen in Fig. 3, the effect of temperatures in the bricks containing $\mathrm{BCW}$ was negligible. The porosity of the brick increased slightly due to the release of $\mathrm{CO}_{2}$ gas during decomposition and the lack of full adhesion of the $\mathrm{BCW}$. The increase in the porosity of the brick helps improve thermal insulation properties. In cement based composites, it is necessary to increase porosity to obtain high thermal insulation performance. Therefore, air entraining agent and expanded polystyrene (EPS) are used in the buildings. However, their use increases the cost. Furthermore, EPS loses its function when it is exposed to fire. The increase in the porosity of both cement-based and clay-based composites generally leads to a decrease in strength. However, the bricks containing BCW do not show significant strength loss. 


\subsubsection{Water absorption}

The water absorption values of the produced bricks are presented in Figure 4. As it is seen in Fig. 4, water absorption values ranged from $16.1 \%$ to $20.4 \%$. The lowest water absorption value was obtained in $\mathrm{P} 0$ with the lowest porosity and the highest bulk density. The highest water absorption value was observed in S4 with the highest porosity and the lowest bulk density.

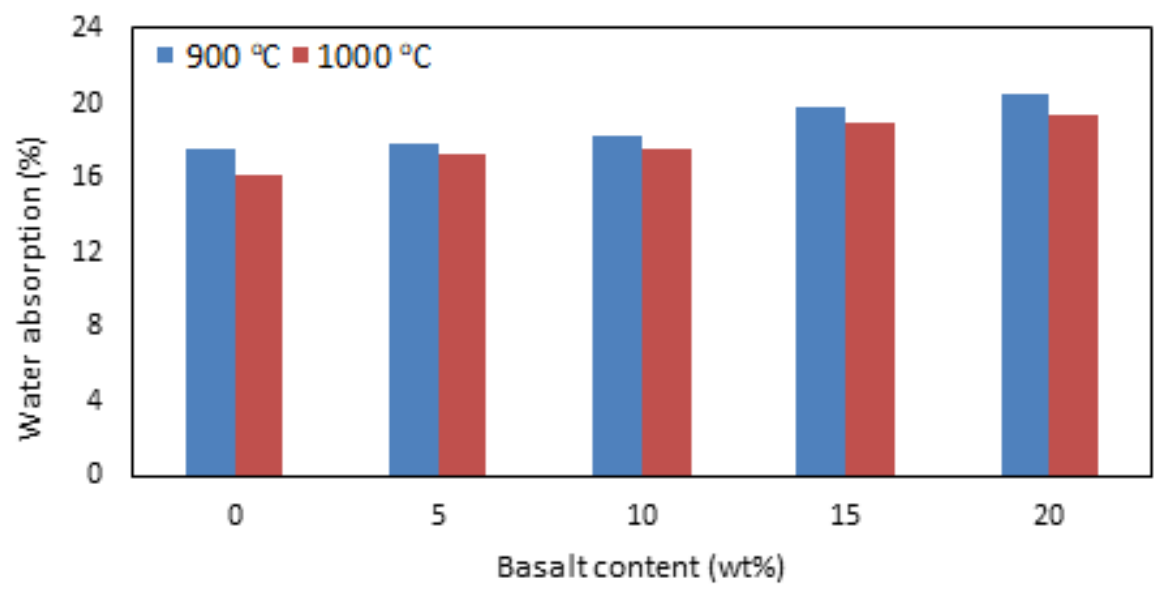

Figure 4. Water absorption of the produced bricks.

\subsubsection{Compressive strength}

Compressive strength is the most important property of construction materials. In many countries, clay bricks are allowed up to be used up to three storeys in building applications. Therefore, it is known that bricks should have a minimum compressive strength of $7 \mathrm{MPa}$ according to Turkish and relevant European Standards (TS EN 771-1). As it is seen in Fig. 5, the compressive strength of the samples produced was decreased depending on the concentration of $\mathrm{BCW}$ in the brick for both temperatures.

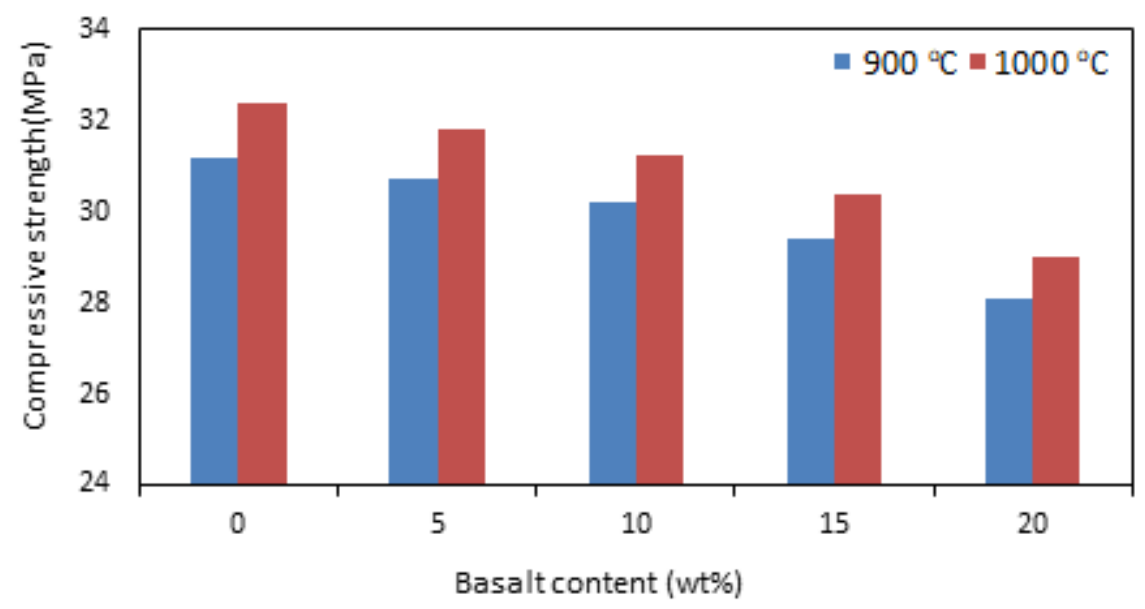

Figure 5. Compressive strength of the produced bricks. 
Compressive strength values ranged from 28,1 MPa to 32,4 MPa. The highest strength samples observed in the samples produced were observed in P0 (32.4 MPa) and S0 (31.2 MPa) reference samples. Among the samples, the lowest strength values were observed in S4 (28.1 MPa) and P4 (28.9 MPa) with a concentration of $20 \% \mathrm{BCW}$. The compressive strengths of S1, S2, S3 and S4 containing BCW were found to be lower by $1.5 \%, 3.2 \%, 5.8 \%$ and $10 \%$, respectively, compared to S0. The compressive strengths of $\mathrm{P} 1, \mathrm{P} 2, \mathrm{P} 3$ and $\mathrm{P} 4$ containing $\mathrm{BCW}$ were found to be lower by $1.8 \%, 3.6 \%, 6.3 \%$ and $11.5 \%$, respectively, compared to $\mathrm{B} 1$. With this comparison, it was understood that $\mathrm{BCW}$ had a significant effect on the compressive strength of the clay brick, and that the effect of temperature was low. Although the bricks lost their strength, all bricks still had high compressive strength. The reason underlying the loss of pressure is related to the porosity of the brick. The values obtained are very suitable for structural applications even in earthquake zones. When density and compressive strength are evaluated together, the bricks produced provided superior values compared to lightweight concrete. When the relationship between porosity and compressive strength was examined, compressive strength decreased while porosity increased. Furthermore, it can be concluded that BCW utilization rate in the samples may increase by more than $20 \%$. Many lightweight concrete containing perlite, vermiculite and expanded polystyrene (EPS) for insulation purposes generally have low compressive strength and are not sufficient for structural applications [30,31]. The bricks with BCW have the thermal insulation and durability required for structural applications. Nevertheless, further studies should be carried out by adding some additives (vermiculite, pumice, perlite, etc.) to the sample to see the effects of mineral additives such as BCW on the properties of bricks.

\subsubsection{Thermal conductivity}

The thermal conductivity results of the bricks produced are presented in Figure 6. The thermal conductivity values of the reference samples ( $\mathrm{S} 0$ and $\mathrm{P} 0$ ) were 0.98 and $1.12 \mathrm{~W} / \mathrm{m} \mathrm{K}$, respectively. The thermal conductivity value of the samples decreased to $0.72 \mathrm{~W} / \mathrm{m} \mathrm{K}$ (sample S4) depending on the amount of BCW added to the clay brick mixture.

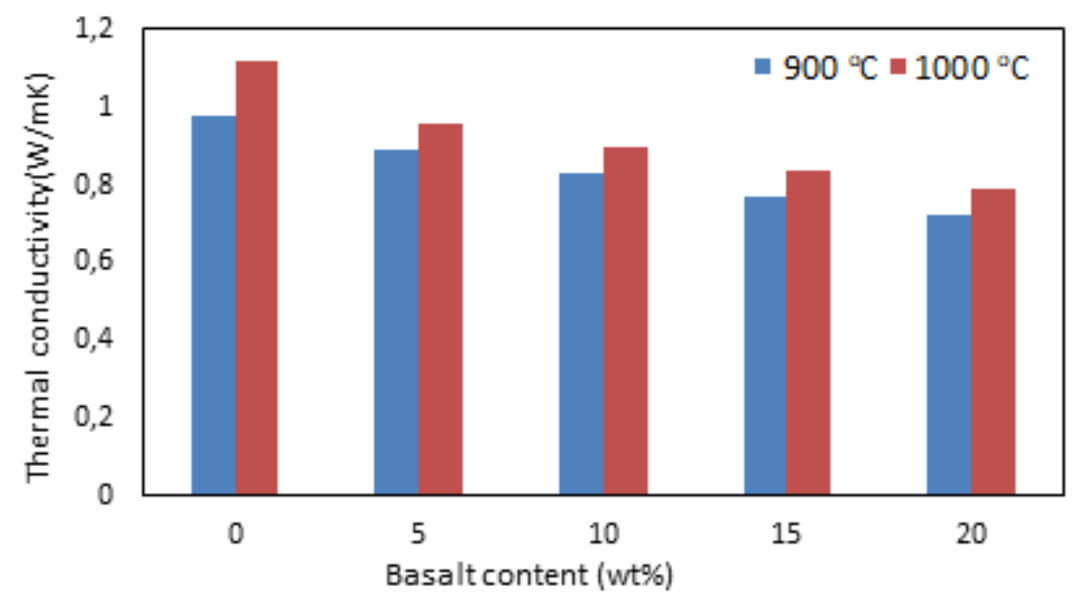

Figure 6. Thermal conductivity of the produced bricks.

Fig. 6 also shows a comparison of thermal conductivities in each group and at each temperature. The thermal conductivity values of $\mathrm{S} 1, \mathrm{~S} 2, \mathrm{~S} 3$ and $\mathrm{S} 4$ containing BCW were found to be lower by $9.18 \%$, $15.3 \%, 21.4 \%$ and $26.5 \%$, respectively, compared to S0. The thermal conductivity values of P1, P2, P3 and $\mathrm{P} 4$ containing $\mathrm{BCW}$ were found to be lower by $14.17 \%, 19.73 \%, 25 \%$ and $29.6 \%$, respectively, 
compared to $\mathrm{P} 0$, which was due to the increased porosity of the brick. These results indicated that the thermal performance of the bricks should be improved by the use of additional pore-forming materials in the brick.

\section{Conclusions}

In this study, the usability of BCW in brick production was examined. Clay brick samples with different proportions of $\mathrm{BCW}$ were produced. The key results of the use of $\mathrm{BCW}$ in the production of fired clay bricks are as the following.

- The bulk brick density decreased to $1.73 \mathrm{~g} / \mathrm{cm}^{3}$ at $900^{\circ} \mathrm{C}$ and up to $1.82 \mathrm{~g} / \mathrm{cm}^{3}$ at $1000^{\circ} \mathrm{C}$ with BCW depending on its content in the mixture.

- Although lower density was observed at $900^{\circ} \mathrm{C}$, the effect of temperature on bulk density was smaller and negligible. It is extremely important to reduce the bulk density of the bricks in order to decrease the dead building load. The reduction of the dead load decreases the sections of the load bearing elements of the building.

- $\quad$ BCW had a significant effect on sample porosity. The addition of BCW increased the porosity of fired bricks up to $34 \%$. The effect of temperature changes on brick porosity was insignificant. The increase in the amount of $\mathrm{BCW}$ in the bricks resulted in an increase in the thermal insulation performance of the bricks.

- Water absorption of the bricks increased depending on the increase in the amount of BCW. There was a close relationship between water absorption and brick porosity. Higher porosity led to higher water absorption.

- The bricks with 5-20\% BCW added to the brick clay had a compressive strength of 28.08-32.38 MPa above $7 \mathrm{MPa}$ as required by the standard. Compressive strength is very important for load bearing elements of walls. The compressive strength of the samples with the addition of BCW was found to be lower compared to the compressive strength of the reference brick at both temperatures. Moreover, it was observed that all bricks with the addition of $\mathrm{BCW}$ were found to have greater strength than $18 \mathrm{MPa}$, which can be used in structural applications, meeting the disaster regulation for a building material that meets the requirement of TS EN 771.

- The addition of BCW increased the thermal performance of bricks. The thermal conductivity of the brick was related to porosity. Nevertheless, thermal insulation performance of bricks could be improved by the use of additional pore-forming materials in the brick. Therefore, further studies on different BCW concentrations, combinations and pore-forming agents should be carried out to see the effects of structural composites on both physical, physico-mechanical and thermal performance. The raw materials of the produced samples and the microstructures of the composites are very important to achieve the desired results. As it was clearly understood from the test results in this study, the bricks containing BCW have superior properties compared to lightweight concrete containing $\mathrm{BCW}$, which clearly indicates the high potential for the use of $\mathrm{BCW}$ in clay. Furthermore, it is necessary to study the combination of different additives and the properties of $\mathrm{BCW}$ bricks. 


\section{References}

[1] Balaras, C.A., Droutsa, K., Argiriou, A.A., Asimakopoulos, D.N. (2000). Potential for energy conservation in apartment buildings. Energy and Buildings, 31 (2), 143-154.

[2] EN832 Standard. Thermal Performance of Buildings: Calculation of Energy Use for Heating Residential Buildings CEN, Brussels, Belgium, 1998.

[3] del Coz Díaz, J., García Nieto, P.J., Suárez Sierra, J.L., Penuelas, Sánchez, I. (2008). Non-linear thermal optimization and design improvement of a new internal light concrete multi-holed brick walls by FEM. Applied Thermal Engineering, 28 (8), 1090-1100.

[4] Sutcu, M. Akkurt, S. (2009). The use of recycled paper processing residues in making porous brick with reduced thermal conductivity, Ceramics International. 35 (7,) 2625-2631.

[5] Sutcu, M., del Coz Díaz, J.J., Álvarez Rabanal, F.P., Gencel, O., Akkurt, S. (2014). Thermal performance optimization of hollow clay bricks made up of paper waste. Energy and Buildings. 75 96-108.

[6] Sutcu, M. (2014). Influence of expanded vermiculite on physical properties and thermal conductivity of clay bricks. Ceramics International. 41 (2). 2819-2827.

[7] Gencel, O. (2015). Characteristics of fired clay bricks with pumice additive. Energy and Buildings, $102,217-224$.

[8] Ashmarin, A.G., Vlasov, A.S. (2005). Wall ceramics from zeolite-bearing argillaceous materials, Glass and Ceramics, 62 (9-10), 314-316.

[9] Akpinar, E. K., Koçyigit, F. (2016). Thermal and mechanical properties of lightweight concretes produced with pumice and tragacanth. Journal of Adhesion Science and Technology, 30(5), 534553.

[10] Koçyiğit, Ş., Çay, V.V. (2017). Mechanical properties of the composite material produced by the mixture of expanded perlite, waste marble dust and tragacanth. European Journal of Technique, $8(2), 124-133$.

[11] Gencel, O., Sutcu, M., Erdogmus, E., Koc, V., Cay, V.V., Gok, M. S. (2013). Properties of bricks with waste ferrochromium slag and zeolite. Journal of cleaner production, 59, 111-119.

[12] Dondi, M., Mazzanti, F., Principi, P., Raimondo, M., Zanarini, G. (2004). Thermal conductivity of clay bricks. Journal of Materials in Civil Engineering, 16(1), 8-14.

[13] Görhan, G., Şimşek, O. (2013). Porous clay bricks manufactured with rice husks. Construction and Building Materials, 40, 390-396.

[14] Raut, S. P., Ralegaonkar, R. V., Mandavgane, S. A. (2011). Development of sustainable construction material using industrial and agricultural solid waste: A review of waste-create bricks. Construction and Building Materials, 25(10), 4037-4042.

[15] Al-Hazmy, M. M. (2006). Analysis of coupled natural convection-conduction effects on the heat transport through hollow building blocks. Energy and Buildings, 38(5), 515-521. 
[16] Cay, V. V., Sutcu, M., Gencel, O., Korkut, T. (2014). Neutron radiation tests about FeCr slag and natural zeolite loaded brick samples. Science and Technology of Nuclear Installations, Volume 2014, 5 pages

[17] Rimpel, E., Rehme, F. (2001). Development of extruded high-thermal insulating bricks. ZI International, 54(12), 36-41.

[18] Zhang, L. (2013). Production of bricks from waste materials - a review, . Construction and Building Materials, 47 643-655.

[19] Valášková, M., Martynková, G. S., Smetana, B., Študentová, S. (2009). Influence of vermiculite on the formation of porous cordierites. Applied Clay Science, 46(2), 196-201.

[20] Koksal, F., Gencel, O., Brostow, W., Lobland, H. H. (2012). Effect of high temperature on mechanical and physical properties of lightweight cement based refractory including expanded vermiculite. Materials Research Innovations, 16(1), 7-13.

[21] Uz, B. (2001). Sert Mermer Grubuna Bir Örnek; Diyarbakır Karacadağ Bazaltlarının Mermer Açısından İncelenmesi. Türkiye III. Mermer Sempozyumu Bildiriler Kitabı. Afyon, 43-53.

[22] Işık, N., Yıldız, S., Keleştemur, O. (2008). Investigation of the Mechanical Properties of Basalt Stones in the Diyarbakır-Karacadağ. Science and Eng. J of Firat Univ, 20(4), 617-626.

[23] KAHVECI, A. E., KadayifÇi, A. (2013). Investigation structural properties of basalt stone in diyarbakir region. Uluslararası Teknolojik Bilimler Dergisi, 5(3), 56-69.

[24] Hassan, M.Y. (2001). Basalt Rock as an Alternative Raw Material in Portland Cement Manufacture. Materials Letters, 50, 172-178.

[25] Al-Harthi, A.A., Al-Amri, R.M., Shehata, W.M. (1999). The Porosity and Engineering Properties of Vesicular Basalt in Saudi Arabia, Engineering Geology, 54, 313-320.

[26] Franzone, J.G. (1980). Geology Geotechnical Properties and Vesicular Rock Classification of Lousetown Basalt And Lattices Truckee Area California, M.Sc. Thesis, Unpuplished University of Nevada.

[27] Tugrul, A., Gurpinar, O. (1997). A Proposed Weathering Classification for Basalt and Their Engineering Properties (Turkey), Bulletin of Engineering Geology and the Environment, 55, 139149.

[28] Houston, E. C., Smith, J. V. (1997). Assessment of Rock Quality Variability due to Smectitic Alteration in Basalt Using X-Ray Diffraction Analysis. Engineering Geology, 46, 19-32.

[29] Korkanç, M., Tuğrul, A. (2005). Evaluation of Selected Basalts from the Point of Alkali-Silica Reactivity. Cement and Concrete Research, 35, 505-512.

[30] Cha, J., Seo, J., Kim, S. (2012). Building materials thermal conductivity measurement and correlation with heat flow meter, laser flash analysis and TCi. Journal of thermal analysis and calorimetry, 109(1), 295-300.

[31] Shannag, M. J. (2011). Characteristics of lightweight concrete containing mineral admixtures. Construction and Building Materials, 25(2), 658-662.

[32] Schackow, A., Effting, C., Folgueras, M. V., Güths, S., Mendes, G. A. (2014). Mechanical and thermal properties of lightweight concretes with vermiculite and EPS using air-entraining agent. Construction and Building Materials, 57, 190-197. 